\title{
Laser-assisted water condensation in the atmosphere: A step towards modulating precipitation?
}

\author{
J. Kasparian' ${ }^{1}$, P. Rohwetter ${ }^{2}$, L. Wöste ${ }^{2}$, J.-P. Wolf ${ }^{1}$
}

\begin{abstract}
1. GAP-Biophotonics, Université de Genève, Chemin de Pinchat 22, CH-1211 Genève 4, Switzerland.E-mail: jerome.kasparian@unige.ch
\end{abstract}

2. Institut für Experimentalphysik, Freie Universität Berlin, Arnimallee 14, D-14195 Berlin, Germany

\begin{abstract}
We review the recent results about laser-induced condensation based on self-guided filaments generated by ultrashort laser pulses. After recalling the physico-chemistry of cloud particle formation in the atmosphere and the physics of laser filamentation, we discuss experimental results on laser-induced condensation and its relevance for modulating precipitations.
\end{abstract}

\section{Introduction}

As vital natural resource for life, water has been the object of attempts to control or modulate its cycle since the ancient times. Such efforts primarily aimed at favoring its use via irrigation, seawater desalination, or harvesting it from the atmosphere. They also concerned the prevention of disasters, like flooding or damage caused by hail, and the prediction of atmospheric conditions.

Most civilizations developed magic or religious practice aiming at controlling the weather, and in particular precipitation. The first scientific attempts rely on the observation that clouds convert only few per cent to a few tens of per cent of the available humidity into precipitation, leaving a wide room for improving the process "yield". The experiments date back to 1934, when the former Soviet Union launched programs of airborne cloud seeding using calcium chloride [1]. After World War II, this activity developed further, with seeding by dry ice and silver iodide, both in the USSR and in the US with the well-known experiments from Langmuir and Schafer $[2,3,4]$.

Since then, several approaches have been proposed in order to enhance precipitation by cloud seeding. Among them, static cloud seeding is both the oldest one [1-4] and still the most widespread today. It consists in injecting dry ice or silver iodide particles into cold clouds. Their molecular structure close to that of ice helps converting supercooled water droplets into ice, a state in which they are expected to grow faster. Alternatively, dynamic seeding aims at quickly converting supercooled water into ice particles in order 
to release latent heat that will in turn enhance convection and updrafts and finally allow the clouds to grow larger and harvest more water vapor from the atmosphere [5]. Finally, hygroscopic seeding of warm (e.g., tropical) clouds relies on the injection of artificial cloud condensation nuclei (CCN), i.e., droplet embryos of sub- $\mu \mathrm{m}$ to a few $\mu \mathrm{m}$ in size, made of water or hygroscopic salts to produce water droplets. For example, largescale experiments are conducted in that direction in Colorado [6]. The main challenge faced by this technique resides in adequately choosing the right embryo size and dispersing them efficiently while keeping them inside the active cloud volume. The latter difficulty can be addressed at least in part by using airborne pyrotechnic flares, which also have the advantage of reducing the required amount of necessary salt mass [7].

However, the efficiency of cloud seeding is still controversial $[7,8,9]$. This controversy is fueled by the intrinsic variability of the atmosphere in both time and space, raising the need for large samples in order to obtain statistically significant results. In particular, the atmospheric variability and its dynamics make it extremely difficult to identify which seeding technique can be efficient and under which conditions [7].

This question may soon get an even broader scope. Ultrashort laser pulses were observed to generate highly hygroscopic species [10], resulting in the nucleation of nanometric and micrometric particles [11,12]. This raised the prospect for laserinduced cloud seeding. Here, we review the recent results in this fast emerging field and discuss the applicability of laser-induced condensation to cloud seeding. This review is organized as follows. In Section III, we review the experimental results about laserinduced condensation, the interpretation and modelling of which is detailed in Section IV. Finally, Section V discusses the applicability of laser-induced condensation to cloud seeding and remote sensing. However, before directly discussion laser-induced nucleation, we will provide in Section II an overview of the required background knowledge about both the physics and chemistry of particle formation in the atmosphere, and about the non-linear propagation of intense ultrashort lasers and the resulting filamentation.

\section{Background}

\section{II.1. Physico-chemistry of cloud particle formation in the atmosphere}

Understanding the mechanisms of laser-induced condensation requires previous knowledge about the physico-chemistry of particle nucleation and water condensation. The present section summarises the essential data on this issue. For further details about nucleation in the context of atmospheric physics, the reader is referred to reference books $[13,14]$.

\section{II.1.a. Thermodynamics of particle nucleation}

In the context of atmospheric science, nucleation refers to the formation of condensed material (ice, liquid or aqueous phase) from the gas phase. In the following, we shall focus the discussion on liquid particles, which are more relevant in the lower troposphere, down to $-20^{\circ} \mathrm{C}$. Nucleation is discontinuous, since a phase boundary is created between the forming liquid particle and the surrounding gas. It is called heterogeneous when it initiates on inhomogeneities like pre-existing nanoparticles 
named condensation nuclei, which have the ability to grow by harvesting matter from the gas to the liquid phase. Heterogeneous nucleation is supported by the abundance of atmospheric aerosols, especially in the troposphere. Conversely, nucleation occurring without condensation nuclei is termed homogeneous. Homogeneous nucleation is called homomolecular if one single species is involved and heteromolecular if several species condense together.

The foundations of the classical nucleation theory $[13,14]$ have been set by J. W. Gibbs in the second half of the 19th century. Phase changes between the liquid and gas phases separated by an infinite plane interface are thermodynamically favourable if they reduce the Gibbs energy of the whole system (i.e., both the gas and condensed phases) [15]: $G=U+p V-T s$, where $U$ is the internal energy, and $T$ and $s$ are the temperature and entropy of the system, $V$ the volume it occupies, and $p$ its pressure. By definition of the chemical potential $\mu$, at a constant temperature and pressure, the Gibbs energy can also be derived from the chemical potential $\mu_{i}$ of each species $i$ and the corresponding number of moles $n_{i}$ :

$$
G=\sum_{i=1}^{k} \mu_{i} n_{i}
$$

The chemical potential of gaseous species is obtained by considering them as ideal gases:

$$
\mu_{i}(T)=\mu_{i}\left(T, p_{\circ}\right)+R T \ln \left(\frac{p_{i}}{p_{\circ}}\right)
$$

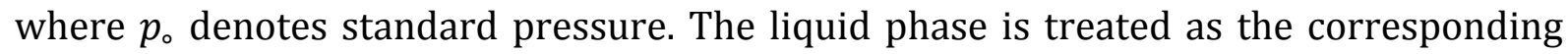
bulk liquid, ignoring effects of molecular orientation or conformation in nanometric clusters [16].

In the case of particle nucleation and growth, the Gibbs energy is not only defined by the chemical potentials. Rather, it is also affected by the curvature of the interface between the liquid and gas phases, i.e., the particle surface. This influence stems from the surface tension, which is curvature-dependent. Its most important contribution to the Gibbs energy is the work needed to form the phase boundary. Considering a spherical droplet with radius $r$, the capillarity approximation yields a surface energy

$$
G_{\text {Surface }}=4 \pi r^{2} \sigma
$$

$\sigma$ being the surface tension of the bulk (i.e., for a plane, infinite surface). This positive term tends to increase the Gibbs energy, hence to reduce the particle stability and the condensation and oppose the particle growth. The total change in Gibbs energy due to the condensation of $n$ moles of gas into a spherical liquid droplet expresses as:

$$
\Delta G=n\left(\mu_{\ell}-\mu_{v}\right)+\Delta G_{\text {Surface }}
$$


where the subscripts $\ell$ and $v$ stand for the liquid and vapor phases, respectively. For ideal gases, the first term can be expressed in terms of the vapour pressure $p_{g}$ and the saturation vapour pressure over a flat phase boundary $p_{g}^{\circ}$ :

$$
\mu_{l}-\mu_{v}=-R T \ln \left(\frac{p_{g}}{p_{g}^{\circ}}\right)=R T \ln (S)
$$

where $S$ is called the saturation ratio, or relative humidity (RH) when expressed in percentage. If $S>1$, considering that chemical potentials are smaller in the liquid phase $\left(\mu_{l}<\mu_{g}\right)$, this term may balance the surface energy term, thermodynamically allowing condensation, i.e. particle growth. In the case of homogeneous homomolecular nucleation, Equation (4) rewrites as

$$
\Delta G=-\frac{4 \pi}{3} \frac{k_{B} T}{v_{\ell}} \ln (S) r^{3}+4 \pi r^{2} \sigma
$$

where $k_{B}$ is Boltzmann's constant, and $v_{\ell}$ is the volume occupied per molecule in the liquid phase. In a supersaturated atmosphere $\left(S>1\right.$ ), $\Delta G$ reaches a maximum $\Delta G^{*}$ (or Gibbs energy barrier) at a so-called critical radius

$$
\begin{gathered}
r_{\text {crit }}=2 \frac{\sigma v_{\ell}}{k_{B} T \ln (S)} \\
\Delta G^{*}=\Delta G\left(r_{\text {crit }}\right)=\frac{4 \pi}{3} \sigma r_{\text {crit }}^{2}=\frac{16 \pi}{3} \frac{\sigma^{3} v_{\ell}^{2}}{\left(k_{B} T \ln (S)\right)^{2}}
\end{gathered}
$$

Since $r_{\text {crit }}$ depends on the saturation ratio, one can alternatively define the equilibrium saturation ratio $S_{e q}$ maximizing $\Delta G$ for a given radius $r$ :

$$
S_{e q}(r)=\exp \left(\frac{2 \sigma v_{\ell}}{k_{B} T r}\right)
$$

$r_{\text {crit }}$ defines the criterion for particle stability at a given relative humidity, as an unstable equilibrium size between particle growth and evaporation. Particles below this radius will evaporate, while particles exceeding it tend to grow indefinitely until they deplete the water vapor available.

\section{II.1.b. Homogeneous homomolecular nucleation}

Homogeneous homomolecular nucleation relies on the collisions of water molecules due to thermal motion. Such collisions form dimers, which may subsequently collide with a third molecule to form a trimer, etc. Equation (6) allows determining the population of clusters as a function of the number of water molecules they contain, at thermodynamic equilibrium. The nucleation rate $J$ can then be computed as the number of clusters per unit volume and time that exceed $r_{\text {crit }}$, thus entering in the growing regime:

$$
J=A \exp \left[-\frac{\Delta G^{*}}{k_{B} T}\right]
$$

where $A$ depends on the partial vapor pressure of the condensing species and on the composition of the clusters. In the case of homomolecular homogeneous nucleation [14], 


$$
J=\left(\frac{2 \sigma}{\pi m}\right)^{\frac{1}{2}} \frac{v_{\ell} N_{g}^{2}}{S} \exp \left[-\frac{\Delta G^{*}}{k_{B} T}\right]
$$

Here, $N_{g}$ is the number density of vapor monomers and $m$ the mass of a monomer. The term in $\ln (S)^{-2}$ in the definition of $\Delta G^{*}$ governs the strong dependence of $J$ with saturation. As displayed in Figure 1, homogeneous homomolecular nucleation is irrelevant for $S \leq 3$ in standard conditions, so that it plays no significant role in ambient conditions.

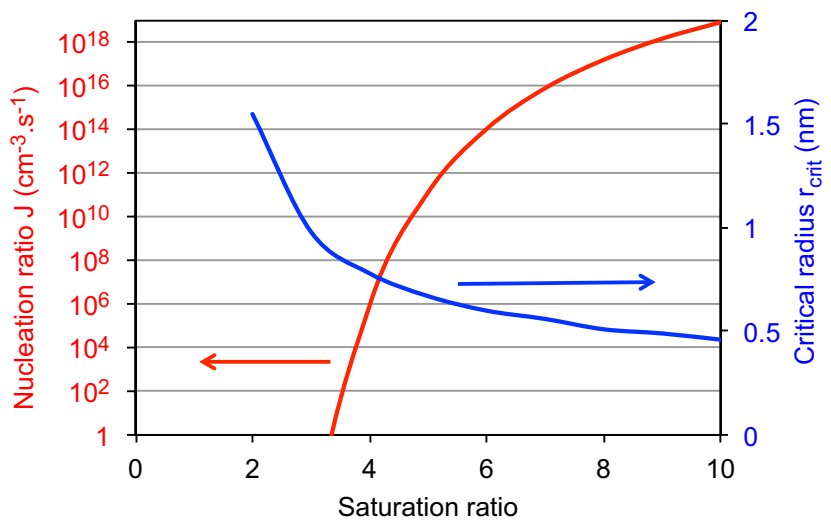

Figure 1. Homogeneous nucleation rate and critical radius for water at $20^{\circ} \mathrm{C}$, calculated using Equation (11)

\section{II.1.c. Homogeneous heteromolecular nucleation}

While homomolecular homogeneous nucleation is inefficient in typical atmospheric conditions, the mutual dissolution of water with a hygroscopic species like $\mathrm{H}_{2} \mathrm{SO}_{4}$ or $\mathrm{HNO}_{3}$ substantially speeds up aggregation. The dissolution reaction reduces the Gibbs energy of the mixed liquid phase, reducing the equilibrium saturation ratio for each species. Considering two species $a$ and $b$, the Gibbs energy change corresponding to the formation of a mixed nucleus expresses as:

$$
\Delta G\left(n_{a}, n_{b}\right)=n_{\mathrm{a}}\left(\mu_{\mathrm{a}, \ell}\left(n_{a}, n_{b}\right)-\mu_{\mathrm{a}, v}\right)+n_{\mathrm{b}}\left(\mu_{\mathrm{b}, \ell}\left(n_{a}, n_{b}\right)-\mu_{\mathrm{b}, v}\right)+\Delta G_{\text {Surface }}\left(n_{a}, n_{b}\right)(1
$$

$\Delta G\left(n_{a}, n_{b}\right)$ is saddle-shaped [17]. A binary droplet must grow across its ridge, which is most likely to occur close to the saddle point defining the effective Gibbs energy barrier of nucleation in the estimation of the nucleation rate (See Equation (10)). The preexponential factor $A$ depends on the actual path on the saddle surface and cannot be estimated a priori. Furthermore, the influence of the mixing on the surface tension $\Delta G_{\text {Surface }}[14]$ can be difficult to determine.

Heteromolecular homogeneous nucleation occurs efficiently and plays a key role in aerosol production and cloud formation in both the stratosphere and the troposphere. The $\mathrm{H}_{2} \mathrm{SO}_{4}-\mathrm{H}_{2} \mathrm{O}$ system is the most important in that regard $[18,19,29]$. For example, stratospheric aerosols mainly consist of a concentrated aqueous solution of sulphuric acid, supercooled down to $-85^{\circ} \mathrm{C}$. A major fraction of tropospheric particles below $1 \mu \mathrm{m}$ are also sulphuric [20]. This importance is due to the fact that sulfate is both highly hygroscopic and relatively abundant (5-300 ppt in clean atmosphere, up to $10 \mathrm{ppb}$ in 
polluted areas) [14]. $\mathrm{SO}_{2}$ from biogenic (80\%), volcanic, and fuel burning origins [20] is oxidized into $\mathrm{SO}_{3}$ by $\mathrm{OH}$ radicals, and then quickly reacts with $\mathrm{H}_{2} \mathrm{O}$, yielding $\mathrm{H}_{2} \mathrm{SO}_{4}$ [14].

Binary nucleation of as little as $4 \times 10^{7} \mathrm{~cm}^{-3} \mathrm{H}_{2} \mathrm{SO}_{4}$ molecules and various organic compounds oxidized by $\mathrm{OH}$ radicals was also observed in natural conditions, under which tropospheric nucleation can be observed [21]. The chemical affinity of the two species is so high that the critical nuclei contained only one molecule of $\mathrm{H}_{2} \mathrm{SO}_{4}$ and one of the organic species, resulting in nucleation rates one to two orders of magnitude faster than the classical $\mathrm{H}_{2} \mathrm{SO}_{4}-\mathrm{H}_{2} \mathrm{O}$ binary nucleation [22].

Besides $\mathrm{H}_{2} \mathrm{SO}_{4}$, the main hygroscopic species contributing to water condensation in the atmosphere is $\mathrm{HNO}_{3}$ resulting from the oxidation of $\mathrm{NO}$ and $\mathrm{NO}_{2}$, the concentration of which varies from 0.02 to $1000 \mathrm{ppb}$ in urban areas. As will be discussed later, this pathway can be strongly enhanced by laser irradiation.

\section{II.1.d. Heterogeneous nucleation}

Aerosol particles are abundant (up to several $10^{3} \mathrm{~cm}^{-3}$, or even more in urban areas) in the atmosphere, especially in the lower troposphere. These pre-existing solid particles offer a large active surface area per unit air volume, acting as favourable sites for impinging water molecules from the gas phase. Adhesion of these molecules on the particle substrate balances surface tension and reduces the Gibbs energy needed to transfer molecules from the gas phase to the liquid phase. Surface diffusion of condensing molecules may also help them to gather into a liquid nucleus on this surface. The Gibbs barrier is even further reduced by the solvation energy if the aerosol particles are soluble in water, resulting in an abrupt transition from solid to liquid when the $\mathrm{RH}$ rises above a so-called deliquescence relative humidity (DRH), which is as low as 75\% for $\mathrm{NaCl}, 40 \%$ for $\mathrm{NH}_{4} \mathrm{HSO}_{4}$ and $0 \%$ for $\mathrm{H}_{2} \mathrm{SO}_{4}$ at $298 \mathrm{~K}$ [14]. In the latter case, $0 \% \mathrm{DRH}$ means that water uptake can occur at any $\mathrm{RH}$.

The efficiency of heterogeneous nucleation reduces the critical saturation ratio in the atmosphere to $102 \%$ or even below [23]. The presence of aerosol can therefore suppress homogeneous nucleation by harvesting both the needed water and the hygroscopic species from the gas phase.

\section{II.1.e. Ion-induced nucleation}

In the early 20th Century, following the demonstration of the Wilson chamber [24], electric charges were found to reduce the threshold saturation ratio for droplet nucleation [25,26] by lowering the Gibbs energy for a vapour molecule entering a charged cluster. Because of the large dielectric constant of water, it is treated as a conductor in the Classical Kelvin-Thomson (CKT) equation describing charge-assisted nucleation. This equation defines the equilibrium vapour saturation ratio over a charged liquid surface, including the contribution of surface curvature due to Lord Kelvin. However, Tohmfor and Volmer found that experimental data are better reproduced if treating water as a dielectric sphere [26]:

$$
S_{\mathrm{CKT}}=\exp \left[\frac{m_{v}}{k_{\mathrm{B}} T \rho_{\mathrm{H}_{2} \mathrm{O}}}\left(\frac{2 \sigma}{r}-\frac{\left(1-\varepsilon_{\mathrm{H}_{2} \mathrm{O}}^{-1}\right) q^{2}}{32 \pi^{2} \varepsilon_{0} r^{4}}\right)\right]
$$


and considering a value of $\varepsilon_{\mathrm{H}_{2} \mathrm{O}} \simeq 1.85 \ll \varepsilon_{\mathrm{H}_{2} \mathrm{O} \text {,bulk }} \simeq 80$. This deviation from the bulk dielectric constant is due to the reorientation of the permanent dipole moments of the water molecules in the charged particles. However, as displayed in Figure 2, a reasonable amount of charges per particle cannot stabilize clusters beyond a few molecules, except at very high supersaturation well beyond typical atmospheric conditions [27].
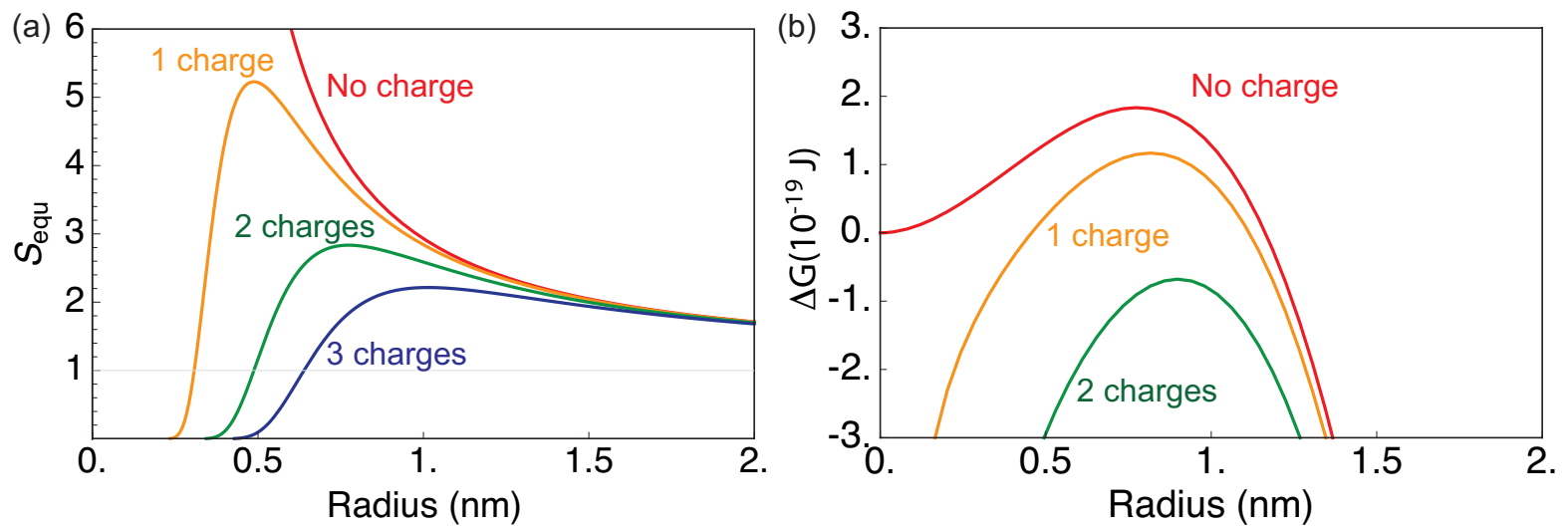

Figure 2. Effect of charge on particle stability at $20^{\circ} \mathrm{C}$. (a) Equilibrium saturation ratio of charged water particles; (b) Gibbs energy barrier of charge-stabilized water particles $100 \% \mathrm{RH}$.

While direct charge-induced water nucleation is not relevant in normal atmospheric conditions where the saturation ratio cannot exceed 1.02 [28,29], modern models of heteromolecular homogeneous nucleation now include effects of electrical charge $[18,19]$ and suggest that ions have an important role in the homogeneous binary $\mathrm{H}_{2} \mathrm{SO}_{4}$ $\mathrm{H}_{2} \mathrm{O}$ nucleation even in the planetary boundary layer, where it competes with efficient heterogeneous nucleation [19].

\section{II.1.f. Activation of atmospheric particles}

Particles are said activated or qualified as droplets if they exceed the critical radius (See Equation (7)), and can in principle grow indefinitely. Activation may result either from a rise in the $\mathrm{RH}$, or from a change of the chemical composition of the surrounding atmosphere, influencing that of the particle, e.g. by allowing the uptake of hygroscopic species like $\mathrm{HNO}_{3}$ or $\mathrm{H}_{2} \mathrm{SO}_{4}$. Unactivated particles are referred to as haze in the context of cloud physics. Particles that can get activated at a RH below the threshold of homogeneous nucleation are named condensation nuclei $(\mathrm{CN})$. Among them, those that get activated at atmospherically relevant $\mathrm{RH}$ (up to 102\%) are named cloud condensation nuclei (CCN) [14].

Close to $100 \% \mathrm{RH}$, tropospheric air contains wet background aerosol, the larger of which can heterogeneously nucleate water vapour at RH slightly above $100 \%$ [13], qualifying them as CCN. Even in clean maritime air, their concentration is close to $100-$ $1000 \mathrm{~cm}^{-3}$. They have diameters in the range of $50-140 \mathrm{~nm}$, depending on their contents in soluble material. 


\section{II.2. Laser filamentation}

Laser filamentation is a propagation regime typical of high-intensity, ultrashort laser pulses. Filamentation in air was discovered accidentally by Braun et al. [30] in an attempt to use such pulses for remote sensing: Unexpectedly, slightly focused $200 \mathrm{fs}$ pulses of "moderate" peak power (13.5 GW) collapsed and damaged remote optical components. They interpreted this phenomenon as a trapped state of self-focusing, balanced by the defocusing lens induced by the negative refractive index contribution of the free electrons from the low-density plasma generated in air at the self-focus.

This dynamical balance between non-linear contributions to the refractive index featuring different orders, hence different intensity dependences is indeed the basis on today's understanding of laser filamentation $[31,32,33]$. It ensures stable, quasi-solitonic propagation of laser filaments over distances up to hundreds of meters [34], with an intensity clamped close to $50 \mathrm{TW} / \mathrm{cm}^{2}[35,36]$, allowing efficient ionization of the propagation medium, as well as the initiation of multiphoton-excited photochemistry. This clamping intensity is understood theoretically as ensuring the dynamic balance between focusing by the Kerr self-focusing on one side, and plasma defocusing [37] as well as the higher-order Kerr effect (HOKE) [38,39] on the other.

The initiation of laser filamentation requires the Kerr self-focusing to balance diffraction, so as to initiate the beam collapse. This occurs as soon as the power exceeds a so-called critical power, which amounts to a few GW in air for $800 \mathrm{~nm}$ pulses [40]. In typical conditions, because of losses, spatial and temporal inhomogeneities of the beam and other perturbations, up to 5 critical powers are required to initiate one filament. If the laser power is further increased beyond this value, the number of laser filaments increases almost linearly with the incident power, and multiple filaments are generated in the beam (Figure 3) at the typical rate of 1 filament for each 5 critical powers [41]. However, this increase is limited by the cross section of the beam profile. Each filament typically needs about $1 \mathrm{~mm}^{2}$ of beam cross-section to develop with its surrounding photon bath, so that the filament number density saturates [42], resulting in an increase of the photon bath intensity that may even end up in its efficient contribution to nonlinear processes [43].

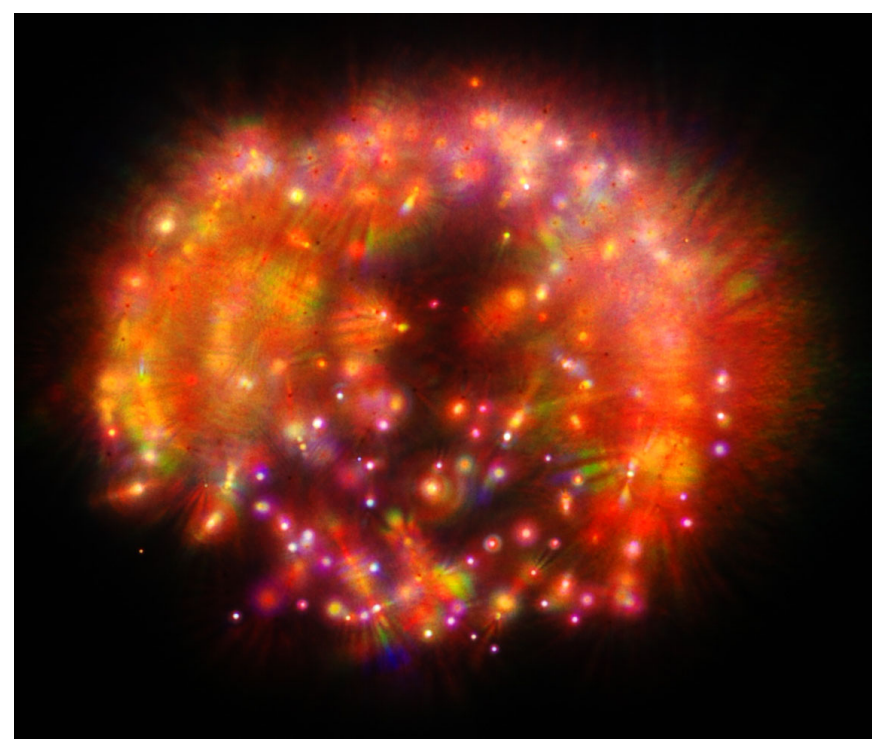


Figure 3. Multiple filamentation of a $3 \mathrm{~J}, 30 \mathrm{fs}$ laser pulse of $10 \mathrm{~cm}$ diameter, imaged in real color on a screen

Laser filaments can be generated at kilometer-range distances $[44,45]$ by adequately tailoring the laser pulses. The main parameters at hand are the beam diameter and focusing, as well as the pulse chirp [46], i.e., the temporal offset of its spectral components related to one another. If the initial pulse chirp is opposite to the atmospheric group-velocity dispersion, the pulse will tend to re-compress at a distance that depends only on the magnitude of the chirp, and can therefore be easily set on demand. From the technical point of view, this is realized easily in chirped pulse amplification (CPA) lasers [47] by slightly varying the distance between the gratings of the compressor.

Furthermore, this long-distance capability can efficiently be exploited for atmospheric applications because of the unexpectedly high robustness of the dynamic balance at the root of filamentation. Filaments have the unique capability to self-heal after being blocked by an obstacle like a water drop because they are replenished by the surrounding photon bath (also known as energy reservoir [48]) [49,50,51]. Conversely, a diaphragm blocking this photon bath arrests filamentation [48]. They can therefore propagate efficiently through rain, or fogs [41], but also through reduced pressures [52] and highly turbulent regions [53,54] without being substantially perturbed. This robustness makes filaments highly suitable for applications in the atmosphere [55,56], which is intrinsically a perturbed propagation medium.

Atmospheric applications have been investigated by several groups, with even real-scale outdoor experiments allowed by the mobile-terawatt laser Teramobile [46] or the T\&T lab [57]. For example, the Teramobile produces $800 \mathrm{~nm}$ pulses of up to $350 \mathrm{~mJ}$ energy in pulses as short as $70 \mathrm{fs}$, at a repetition rate of $10 \mathrm{~Hz}$. It has the unique property of being embedded in a standard 20' freight container equipped with a standard optics laboratory, including air conditioning, vibration control, as well as electrical power and cooling water management.

A first family of applications of filaments aims at using them to improve remote sensing or analysis. The most natural one in this regard is LIght Detection And Ranging (Lidar). In this technique (Figure 4a), a laser pulse is emitted into the atmosphere, and the backward-scattered light is collected by a telescope and recorded as a function of the pulse time of flight, i.e., of distance. The detected light bears information about the transmission as well as the backscattering efficiency by the air molecules (Rayleigh scattering) and by the aerosol particles (Mie scattering). Lidar strongly benefits from the broad supercontinuum [58] generated by the filaments, which ranges from $230 \mathrm{~nm}$ in the ultrviolet [59] up to $14 \mu \mathrm{m}$ in the mid-infrared [60]. This continuum covers absorption bands of most atmospheric pollutants, including ozone, $\mathrm{NOx}, \mathrm{SO}_{2}$, benzene, toluene and other volatile organic compounds (VOCs), opening the way to their simultaneous sensing by a white-light Lidar [61]. The white-light continuum can be produced either directly in the laser filaments [62], or in a krypton gas cell prior to its emission into the atmosphere [63]. Multispectral Lidar (Figure 4b) also provides multichannel information suitable for determining the size distribution of atmospheric aerosols, together with a simultaneous measurement of atmospheric temperature and humidity [64]. This technique, which leaves the atmosphere unaffected, provides a 
comprehensive meteorologically relevant characterization of the atmosphere. This approach using a single laser system potentially offers an unlimited number of information channels in contrast to conventional multispectral Lidars using several independent lasers, each one providing one single wavelength.
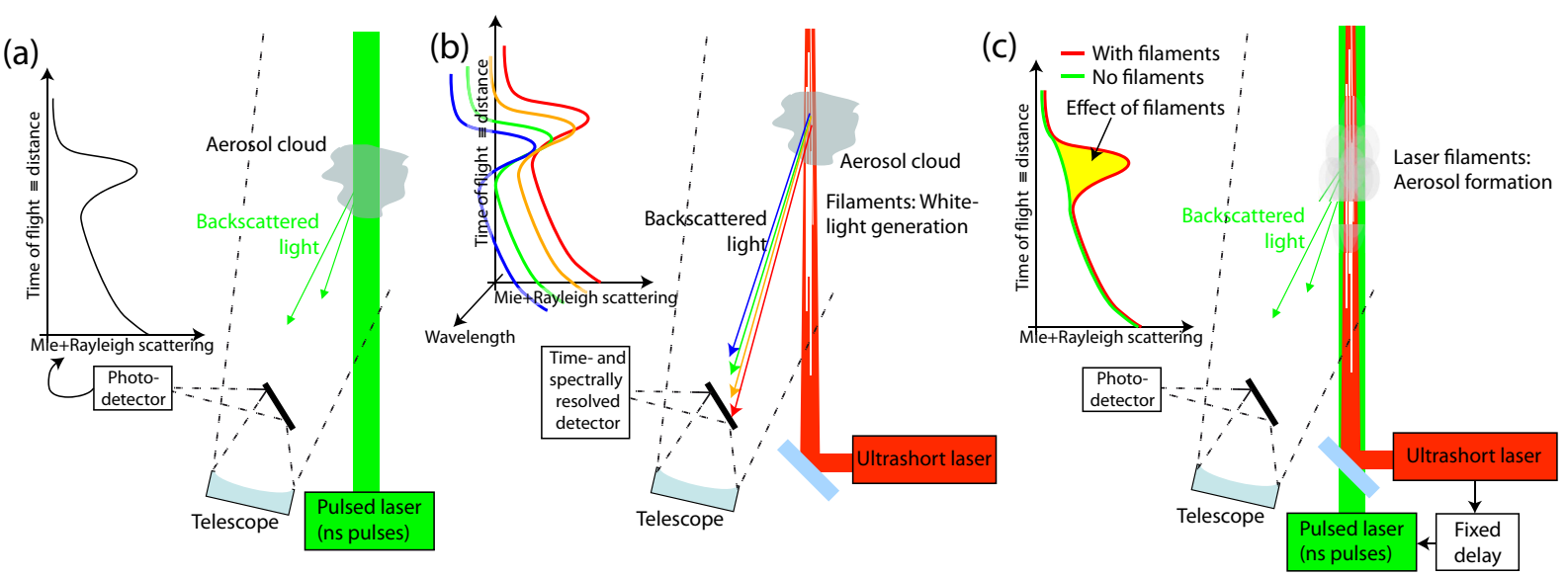

Figure 4. (a) Principle of Lidar. Laser pulses are emitted into the atmosphere. Its backscattered light bears information about the size and number density of the encountered aerosol particles, via their Mie backscattering cross-section. (b) Principle of multispectral (or white-light) Lidar. Filaments generate a broad spectrum upstream of the region to be analyzed, which is left unaffected by the laser but scatters back each wavelength to the detection device. (c) Principle of pump-probe Lidar. Particles are produced in-situ by ultrashort laser filaments in the atmosphere, depending on the atmospheric conditions. These particles are probed after a predefined delay by a Lidar with a beam collinear with the filaments.

An even more powerful variant of femtosecond Lidar takes benefit of the high intensity conveyed by the filaments to non-linearly excite the species to be analysed. Two-photon fluorescence Lidar was applied to remotely detect and identify biological simulants in aerosol droplets [65]. This technique has several advantages over one-photon excited fluorescence-based Lidar, which requires an ultraviolet pump wavelength. The infrared pump is less attenuated by the atmosphere than the ultraviolet, which is much more Rayleigh-scattered (with $\lambda^{-4}$ wavelength dependence) and absorbed by ozone, a drawback which is particularly acute in urban environments where aerosol monitoring is the most relevant. Furthermore, in spherical particles, the non-linear processes like multiphoton-excited fluorescence are preferentially emitted backward due to internal focussing effects in the particles [66]. This backward emission is particularly favourable for remote sensing since the signal is preferentially emitted towards the detection device.

Multiphoton-excited resonance was also proposed to remotely detect gaseous pollutants in the atmosphere [67]. Here, the main advantage resides in the so-called "clean fluorescence" [68]: Due to their low energy for a given peak power, the femtosecond pulses heat the medium very little, so that the fluorescence lines can be detected on a baseline almost free of thermal contributions. The same advantage, as well as the unique capability of the laser filaments to deliver a high intensity at remote distances regardless of diffraction, is at the root of Remote Filament-Induced Breakdown Spectroscopy (RFIBS), a variant of Laser-Induced Breakdown Spectroscopy (LIBS), in which the material to analyse is illuminated by a focused laser beam and the spectrum of the plasma excited at the ablation point is spectrally recorded to provide elemental analysis. Using laser filaments, we detected LIBS signals from several metal samples at a distance of almost 
$200 \mathrm{~m}$ [69], with a very favourable distance scaling since the filaments provide an extended focus with an intensity clamped independently from the propagation distance. The possibility to perform remote measurements together with the fact that LIBS needs no sample preparation make R-FIBS very suitable for the monitoring and/or sorting of dangerous items like nuclear waste, mapping minerals in hard-to-access locations in open-sky mines, or monitoring hot alloys production. This technique was also applied to analyse stone surfaces in cultural heritage buildings [70], as well as explosive simulants [71].

Beyond sensing the atmosphere, ultrashort laser pulses have the unique capability to influence it due to the generation of an underdense plasma channel with typically $10^{15}$ $10^{16}$ electrons $/ \mathrm{cm}^{3}$ over up to hundreds of meters [34], with a typical diameter of $100 \mu \mathrm{m}$, offering a typical resistivity of $1 \mathrm{M} \Omega / \mathrm{m}$. This plasma channel strongly contrasts with the plasma sparks generated by longer pulses. In the latter, the typical nanosecond pulse duration allows efficient avalanche ionization, resulting in a dense plasma opaque to the laser and preventing any long conducting channel to be generated: Even highenergy (several $\mathrm{kJ}$ ) $\mathrm{CO}_{2}$ lasers could guide lightning strikes only with great difficulty $[72,73]$. In contrast, the plasma channels generated by ultrashort laser pulses trigger and guide megavolt-range discharges over several meters [74,75], reducing the breakdown voltage by typically $30 \%$ and offering a straight discharge along the laser beam. Small-scale demonstrations were also performed with UV pulses [76]. Pulse sequences, which enhance the plasma lifetime, further improve the triggering efficiency $[77,78]$. These results open the prospect for guiding lightning strikes $[79,80]$, but also to the remotely measure the electric field [81]. Mapping this atmospheric parameter in 3 dimensions is critically important to understand and model the physics of lightning, but very difficult to measure with classical instruments, which tend to locally perturb the field under measurement.

However, the most spectacular application of femtosecond pulses in the atmosphere is probably laser-induced condensation.

\section{Observation of laser-induced condensation}

\section{III.1. Laboratory results}

The possibility of inducing condensation in a supersaturated atmosphere with laser filaments was mentioned for the first time in 2003, as a way to detect supersaturation [55]. In a first qualitative experiment, the Teramobile team reported strong droplet formation in a cloud chamber saturated with water or isopropanol and illuminated by near-IR laser pulses $(800 \mathrm{~nm})$. The effect was so strong that it was clearly visible with the naked eye, also revealing the turbulent motion of the air blasted by the energy locally deposited by the filament (Figure 5). Under similar conditions $\left(-29^{\circ} \mathrm{C}, \mathrm{RH}\right.$ $\sim 130 \%$ ), laser filaments were observed to produce particles up to $300 \mu \mathrm{m}$, which subsequently sedimented and accumulated within $30 \mathrm{~min}$ as snowflakes on the cold baseplate of the cloud chamber under the laser beam [82]. Strong particle formation was also independently reported in 2005 with $10 \mathrm{~ns}$ pulses of up to $250 \mathrm{~mJ}$ in the ultraviolet at $193 \mathrm{~nm}$ [83]. 


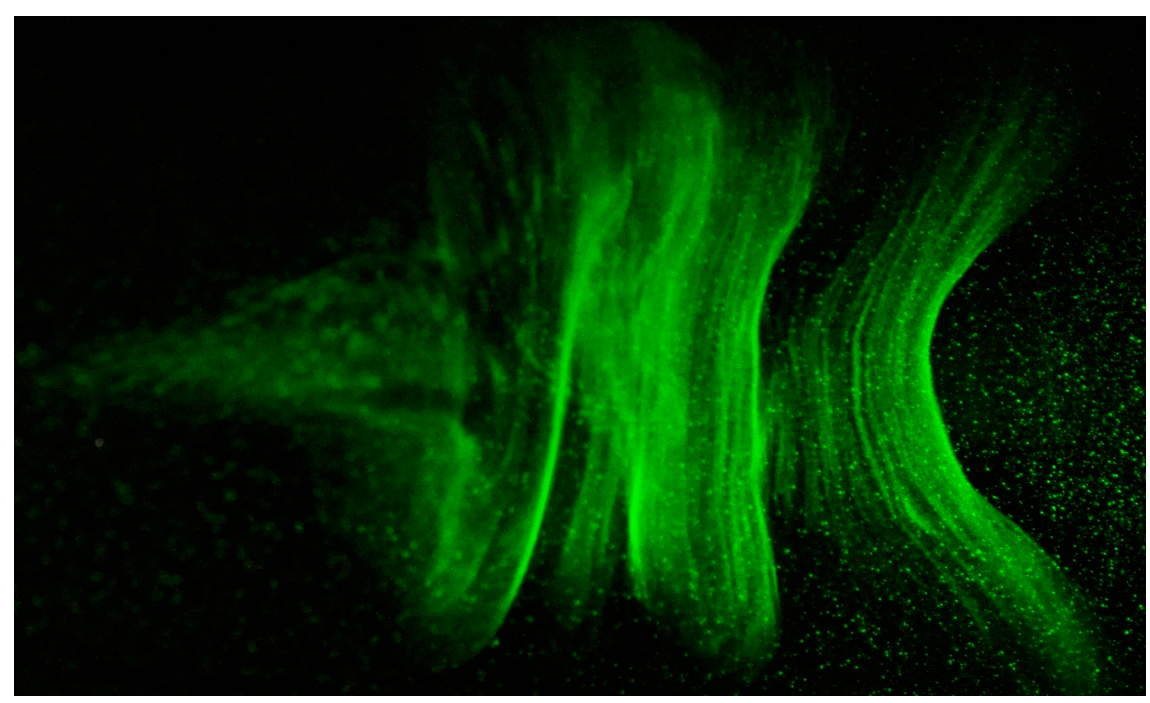

Figure 5. True-color image of laser-induced condensation in a cloud chamber, illuminated by a green auxiliary laser. The main laser features $20 \mathrm{~mJ}$ pulses in $60 \mathrm{fs}$ pulse duration, at a repetition rate of $100 \mathrm{~Hz}$, and is shot continuously over a few minutes. The image is taken with 1600 ISO and an exposure time of $67 \mathrm{~ms}$. The cloud has a transverse dimension in the centimeter-range. Its deformation reveals the air turbulence induced by the blast due to the energy deposited by the laser filament in the atmosphere.

These first observations were, however, not made quantitatively until 2010 [11]. Launching laser filaments in a cloud chamber at a temperature of $-24^{\circ} \mathrm{C}$ and $230 \% \mathrm{RH}$ yielded reproducible and spectacular cloud trails along the laser beam. An optical particle sizer revealed three modes in the size distribution: $4 \mu \mathrm{m}, 50 \mu \mathrm{m}$ and $250 \mu \mathrm{m}$ diameter. These modes also evolved differently after the laser shots. The water contents of the smaller mode kept almost constant. The small particles coalesced, so that their population dropped by half, while the average diameter grew up to $6 \mu \mathrm{m}$. Simultaneously, the medium-sized mode efficiently gained water, with its particles growing from $50 \mu \mathrm{m}$ to $80 \mu \mathrm{m}$ diameter within $3 \mathrm{~s}$ and doubling their number density. This increase was sustained by the laser-induced fragmentation of particles from the larger mode, the remaining particles of which grew up to $400 \mu \mathrm{m}$. As a result, the total condensed water content of the chamber atmosphere increased. Within the active volume, the latter increased by a factor or 100 within $3 \mathrm{~s}$, denoting a condensing rate as high as $5 \mathrm{mg} / \mathrm{cm}^{3} / \mathrm{s}$.

More interestingly, laser filaments had also a dramatic effect also in sub-saturated conditions. Illuminating the air inside the cloud chamber increased the optical scattering signal by a factor of 25 , revealing a substantial condensation of water particles within 4 s, i.e., only 40 laser shots.

\section{III.2. Field measurements}

The same effect was later observed directly in the atmosphere with a relative humidity of $90-93 \%$, and an extremely low background aerosol level, as evidenced by the $70 \mathrm{~km}$ horizontal visibility [11]. The beam of the Teramobile laser was launched vertically. The aerosols were monitored by a classical Lidar synchronized with the femtosecond laser. Between 45 and $75 \mathrm{~m}$ height, where the filaments were most active, their Mie backscattering increased by a factor of 20 when the filamenting beam was active, reaching a value typical of haze $\left(\beta_{\text {Mie }}=2 \times 10^{-5} \mathrm{~m}^{-1} \mathrm{sr}^{-1}\right)[61]$. 
Beyond this demonstration, we gathered a wealth of quantitative data about laserinduced condensation in the atmosphere under a wide range of temperatures $\left(2-36^{\circ} \mathrm{C}\right)$ and RH (35\%-100\%) [12] during a 6 months campaign in Geneva. We compared the particle density close to the laser beam, with that at a reference location (Figure 6). A laser-induced increase of the particle number density is observed over a wide range of diameters, up to a few tens of $\mu \mathrm{m}$. The effect is most spectacular for particles of $\sim 25 \mathrm{~nm}$ diameter. At $75 \% \mathrm{RH}$, the laser multiplied their number density by a factor of 3-6, exceeding $10^{5} \mathrm{~cm}^{-3}$ close to the filaments. Simultaneously, the concentration of $10 \mu \mathrm{m}$ particles increased by $30 \%$. The laser-generated particles were stable over more than $20 \mathrm{~min}$.

The particle generation is accompanied with efficient ozone formation, denoting the activation of efficient plasma chemistry. This chemistry influences particle formation: Ionic chromatography analysis of the laser-generated particles impacted on Teflon filters evidenced high concentrations of $\mathrm{HNO}_{3}$, a hygroscopic molecule detected as dissolved $\mathrm{NO}_{3}$ - ions in concentrations two orders of magnitude above that of $\mathrm{SO}_{4}{ }^{2-}$ in the same particles [12].

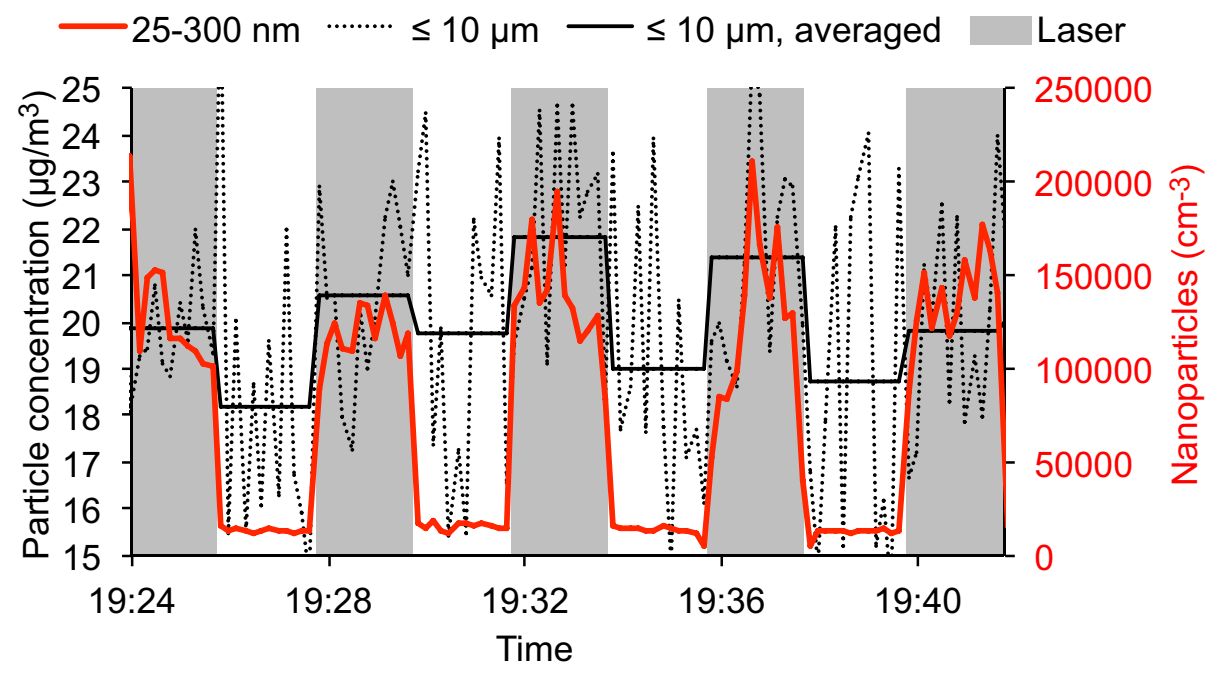

Figure 6. Quantitative observation of laser-induced condensation at 70\% RH. The particle concentration is alternatively sampled close to the laser beam and in reference conditions. The difference between the measured concentrations is attributed to the effect of the laser.

This laser-induced particle formation depends strongly on the water volume mixing ratio (VMR) and RH or the atmosphere, but in a contrasted way for different particle sizes. Figure 7 displays the correlations between the fluctuations of the atmospheric temperature and $\mathrm{RH}$ on one side, with those of the number concentrations of laserinduced particles of each diameter class. The laser-induced formation of particles below $400 \mathrm{~nm}$ correlates with the relative humidity, which can be understood by recalling that the RH determines their thermodynamic stability. Conversely, a second regime emerges for particles above $2 \mu \mathrm{m}$, that are correlated with water VMR. The latter defines the amount of water molecules available per unit volume in the atmosphere to feed the particle growth (See section IV.2). 


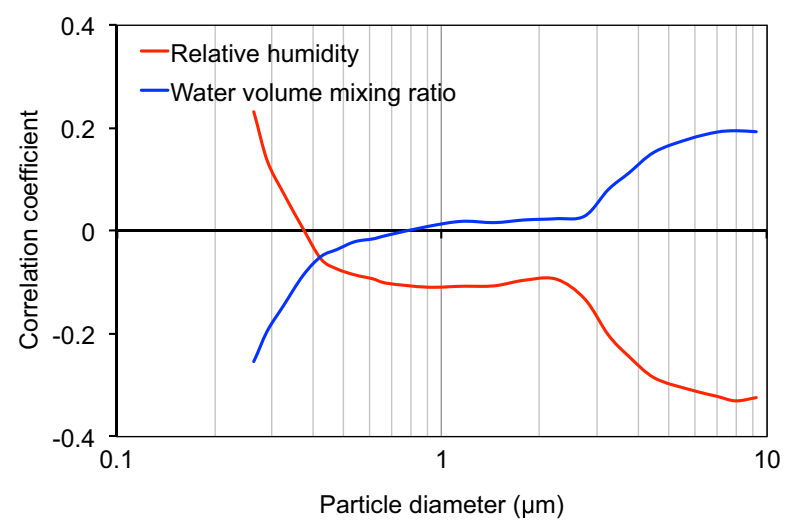

Figure 7. Dependence of the concentration of laser-induced particles of various sizes on the relative humidity and water mixing ratio (after Ref. 12). The graph displays the correlation of the effect of the laser for each size, with the considered atmospheric parameter.

\section{III.3. Scaling of the condensation yield with laser parameters}

The power dependence of the laser-induced particle generation is critical to go beyond small-scale demonstrations and to dimension future systems for potential real-scale applications. Experiments in that regard have been performed on several laser systems, from tabletop systems to terawatt systems (Teramobile [46]), and even to the $100 \mathrm{TW}$ level (DRAC0, 30 J, 100 TW) [84].

At "low" intensity, slightly above the threshold for filamentation, the nanoparticle production is proportional to the incident intensity, i.e., to the filament number $[85,37,38]$. However, above $\sim 500 \mathrm{GW} / \mathrm{cm}^{2}$, the filament number saturates [86] but simultaneously, the number density of nanoparticles increases faster than linearly with the incident intensity. This fast rise is a consequence of an increasing contribution of the photon bath [84] with a $5^{\text {th }}$ (multiphoton dissociation of oxygen leading to the formation of ozone) to $8^{\text {th }}$-order (ionization of $\mathrm{O}_{2}$ ) non-linearity [87].

Furthermore, a third contribution, proportional to the fluence of the photon bath rather than to its intensity, was identified in the case of strongly chirped pulses (i.e., in the picosecond-range) [84]. Finally, neither the sign of the chirp, nor the incident polarization (linear or circular) influence the laser-induced condensation [88]. In contrast, a cumulative effect was suggested by the observation that particle production is more efficient when the laser is emitted as a regular pulse train as compared with the same number of pulses grouped in bursts [82].

\section{Mechanism of laser-induced condensation in atmospheric conditions}

According to the Thomson mechanism [25,26], at high supersaturation ratios, the $10^{15}$ $10^{16} \mathrm{~cm}^{-3}$ charges generated in the laser filaments efficiently trigger nucleation. But as detailed in Section II.1.d this mechanism is irrelevant in atmospheric conditions, as confirmed experimentally by the different intensity dependences of nanoparticle production and the electron generation in the filaments [88]. Rather, the initiation of laser-induced condensation relies on photodissociative processes. For example, only 7 
photons at $800 \mathrm{~nm}$ are required to photodissociate $\mathrm{N}_{2}$, as compared with 11 photons to ionize it $[89,90]$. Even less photons are required at shorter wavelengths, allowing UV light produced by either a nanosecond argon laser or a mercury lamp to efficiently induce condensation [91].

These photochemical processes allow laser filaments to produce considerable amounts of $\mathrm{O}_{3}$ and nitrogen oxides. Up to $400 \mathrm{ppm}$ of ozone and $100 \mathrm{ppm}$ of $\mathrm{NO}_{2}$, respectively, were measured within the filament volume $[10,12]$, leading to the local formation of hygroscopic $\mathrm{HNO}_{3}$ in ppm concentration. The latter was also detected as $\mathrm{NO}_{3}$ - ions dissolved in laser-induced particles of various sizes [12], as well as in laser-induced snowflakes [82], evidencing the role of binary $\mathrm{H}_{2} \mathrm{O}-\mathrm{HNO}_{3}$ nucleation $[19,92,93]$, similar to the binary $\mathrm{H}_{2} \mathrm{SO}_{4}-\mathrm{H}_{2} \mathrm{O}$ condensation $[29,14]$ (See Section II.1.b).

The very complex chemistry occurring in air plasmas [94,95] and of the lack of data on the initial concentrations in the filaments of species like $\mathrm{N}^{*}, \mathrm{~N}_{2}{ }^{*}, \mathrm{~N}^{+}$and $\mathrm{N}_{2}{ }^{+}$do not allow to isolate one single scheme for $\mathrm{HNO}_{3}$ formation. However, one of the main pathways is likely to rely on the fast reaction of $\mathrm{N}^{+}$ions with $\mathrm{O}_{2}$, which at $43 \%$ yields [96]:

$$
\mathrm{N}^{+}+\mathrm{O}_{2} \rightarrow \mathrm{NO}^{+}+\mathrm{O}^{\cdot}
$$

The oxygen radical $\mathrm{O}^{\bullet}$ immediately reacts with $\mathrm{O}_{2}$ to form ozone, which in turn oxidizes the $\mathrm{NO}^{+}$ion, after its capture of a free electron:

$$
\begin{gathered}
\mathrm{O} \cdot \mathrm{O}_{2}+\mathrm{M} \rightarrow \mathrm{O}_{3}+\mathrm{M} \\
\mathrm{NO}+\mathrm{O}_{3} \rightarrow \mathrm{NO}_{2}+\mathrm{O}_{2} \\
\mathrm{NO}_{2}+\mathrm{O}_{3} \rightarrow \mathrm{NO}_{3}+\mathrm{O}_{2}
\end{gathered}
$$

The resulting high concentrations of $\mathrm{NO}_{2}$ and $\mathrm{NO}_{3}$ allow efficient formation of $\mathrm{N}_{2} \mathrm{O}_{5}$ [14], which immediately reacts with water:

$$
\begin{gathered}
\mathrm{NO}_{2}+\mathrm{NO}_{3}+\mathrm{M} \leftrightarrows \mathrm{N}_{2} \mathrm{O}_{5}+\mathrm{M} \\
\mathrm{N}_{2} \mathrm{O}_{5}+\mathrm{H}_{2} \mathrm{O}(\mathrm{s}) \rightarrow 2 \mathrm{HNO}_{3}
\end{gathered}
$$

The limiting reaction in this chain is Reaction (17), with $k_{17}=3 \times 10^{-17} \mathrm{~cm}^{3} / \mathrm{s}$ [14], which together with the extremely high $\mathrm{NO}_{2}$ and ozone concentrations in the filaments can generate $\mathrm{HNO}_{3}$ in the ppm range.

\section{IV.2. Semi-quantitative modelling of particle stability and growth}

This $\mathrm{HNO}_{3}$-mediated pathway is supported by numerical modelling. Figure 8a displays the Köhler plot for ternary $\mathrm{HNO}_{3}-\mathrm{H}_{2} \mathrm{O}-\mathrm{NH}_{4} \mathrm{NO}_{3}$ particles. The Köhler curve displays the equilibrium water saturation ratio $S_{\text {eq }}$ over spherical particles as a function of their size, as defined by Equation (9). Particles below the curve will tend to evaporate, while particles below the curve will grow until they reach one of its ascending branches. The equilibrium between evaporation and growth is stable on ascending branches of the 
Köhler curve, and unstable at maxima and on descending branches. $S_{\text {eq }}$ reduces down to $70 \%$ in the presence of $4 \mathrm{ppm}$ of $\mathrm{HNO}_{3}$, a typical concentration in the laser filaments. Particles above a few tens of nm can grow until they reach the ascending branch of the Köhler curve at a size of several $\mu \mathrm{m}$. This effect persists up to $30^{\circ} \mathrm{C}$, although its efficiency progressively decreases when the temperature increases. Conversely, the $\mathrm{HNO}_{3}$ concentration in the air has only a moderate influence on the cut-off size of the Köhler plot. Its dilution therefore influences the droplet stabilization only marginally, which makes this model robust with regard to this parameter, which is hardly accessible experimentally.
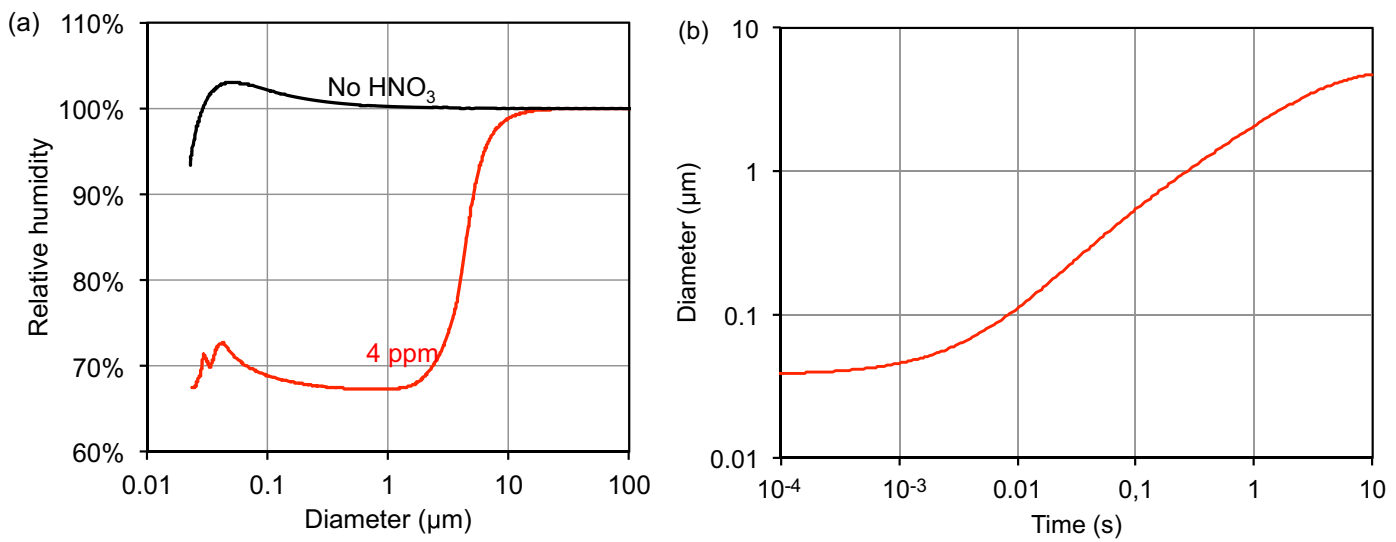

Figure 8. Laser-induced stabilization and growth of a cloud of 1000 particle $/ \mathrm{cm}^{3}$. (a) Köhler plot at $6^{\circ} \mathrm{C}$; (b) Growth of ternary $\mathrm{HNO}_{3}-\mathrm{H}_{2} \mathrm{O}-\mathrm{NH}_{4} \mathrm{NO}_{3}$ particles at $2{ }^{\circ} \mathrm{C}, 90 \% \mathrm{RH}$, and 4 ppm $\mathrm{HNO}_{3}$. (After Ref. 12)

Besides stabilizing particles at $\mathrm{RH}$ well below $100 \%$, the laser-generated $\mathrm{HNO}_{3}$ drastically speeds up their growth. This acceleration is well reproduced by a kinetic model [97] adapted to multi-ppm $\mathrm{HNO}_{3}$ concentrations. Laser-induced particles typically reach a micrometer-sized diameter within $\sim 1 \mathrm{~s}$ or less (Figure $8 \mathrm{~b}$ ), much faster than natural processes [14]. $\mathrm{HNO}_{3}$ first accumulates in the particles during the first $10 \mathrm{~ms}$ of their growth. It is then diluted by efficient water uptake from the gas phase. The droplet growth is ultimately limited by both the amount of $\mathrm{HNO}_{3}$ produced by the laser filaments and by the available humidity. Substantial water vapour depletion occurs as soon as the droplets exceed a few $\mu \mathrm{m}$ in diameter, so that the formation of micrometric particles is correlation with the water VMR (See Figure 7).

In spite of their successes, these models of laser-induced condensation deserve further enhancements to reach completeness. From the physical point of view, polydisperse size distributions should be taken into account. A full dynamic model should also be free of the steady-state approximation and include charge-accelerated coagulation of particles of sub-100 nm size, which could explain the fast appearance of micrometer-sized particles.

From the chemical point of view, a comprehensive model should include the influence of $\mathrm{H}_{2} \mathrm{SO}_{4}$ produced by the laser by oxidizing the background atmospheric $\mathrm{SO}_{2}$ $[29,14,18,19]$, the contribution of hygroscopic $\mathrm{H}_{2} \mathrm{O}_{2}$, and mid-IR atmospheric photochemistry [98], including the excitation of organic peroxyl radicals $\left(\mathrm{RO}_{2}\right)$ [99] or 
water-cluster mediated chemistry [100]. These radicals, originating from the volatile organic compounds present in the atmosphere, subsequently generate hydroxyl $(\mathrm{OH})$ or hydroperoxyl $\left(\mathrm{HO}_{2}\right)$ radicals that are known to contribute to ozone formation. $\mathrm{HO}_{2}$ radicals, which were also measured under UV illumination in concentrations exceeding $200 \mathrm{ppb}$, are produced by the reaction of ozone with $\mathrm{OH}$ radicals [91] and subsequently form hydrogen peroxide $\mathrm{H}_{2} \mathrm{O}_{2}$, a stable and highly hygroscopic molecule efficient at capturing water molecules. Finally, the influence of charge-transfer complexes of $\mathrm{H}_{2} \mathrm{O}^{+} \mathrm{O}_{2}$ - should be investigated. [101].

Furthermore, a full understanding of laser-induced condensation requires considering not only particle growth, but also their direct nucleation from the gas phase. Both homogeneous nucleation, with possible heteromolecular contributions of $\mathrm{H}_{2} \mathrm{SO}_{4}$ and $\mathrm{HNO}_{3}$, and heterogeneous nucleation on mineral or organic condensation nuclei have to be considered. The latter may be activated and made hygroscopic $[102,103,104]$ by the laser-generated ozone or $\mathrm{HNO}_{3}[14,10]$, allowing heterogeneous condensation.

\section{Discussion: Applicability of laser-induced condensation to cloud seeding}

The demonstration of laser-induced condensation raises the question of its applicability and relevance to cloud seeding. By producing particles doped with hygroscopic $\mathrm{HNO}_{3}$ with sub-micrometer to multi-micrometer size comparable to that produced by pyrotechnic flares [105], the laser filaments may be expected to offer artificial CCN and hence to promote the coalescence process in convective clouds. Hygroscopic seeding appears as the most robust cloud seeding technique, with both the most convincing statistical evidence of rainfall increase [105], and support by microphysical modelling $[106,107]$ defining the conditions in which efficient seeding can be expected.

Hygroscopic cloud seeding investigations in the atmosphere have shown that one major limitation of this technique regards the dispersion of the seeding particles, and the risk to provide an excess in these particles, locally reducing precipitation. This is due to the formation of too many small droplets competing for the available water vapor, so that each their growth is limited and they remain too small to undergo droplet collision and coalescence. [108]

In that regard, lasers might offer the opportunity to generate artificial CCN along their beam, with a relatively low local density that further reduces quickly due to dilution from the tiny volume of the laser filaments (typically in the $\mathrm{cm}^{3}$ - range for a TW laser beam) into the open atmosphere. This density can moreover be tuned finely by adjusting the laser power and the duration of its operation. On the other hand, laser beams can be swept across the forming clouds, in which filaments are known to propagate with little perturbation beside the losses due to the scattering of the photon bath [49]. This could allow precisely defining the regions of the cloud where the artificial CCNs would be released. Alternatively, purposely injecting an excess of CCNs could provide a means to temporally reduce precipitation.

Furthermore, the more-than-linear scaling up of the particle generation with the input laser energy [84] may raise the hope for the possibility to effectively seed large cloud 
volumes. Considering the evolution of laser technology, such favourable dependence with the laser energy could be efficiently exploited in the future [109]. The commercially available laser power increased by two orders of magnitude over the last decade, reaching 250 TW nowadays, as compared to a few TW only ten years ago. Peak powers up to the exawatt are even expected in the foreseeable future at the Extreme Light Infrastructure [110].

However, quantitatively assessing both the feasibility of laser-based hygroscopic cloud seeding and its large-scale deployment needs further experimental data as well as theoretical work and modelling. Besides this ultimate dream of seeding clouds, laserinduced condensation may also prove very useful in atmospheric precipitation research by offering new means of mapping in three dimensions the thermodynamic state of the atmosphere, and especially the possibility nucleation and/or condensation within it. Such sensing could be performed in a pump-probe Lidar configuration as described above (See Figure 4c), in which a classical Lidar, with its beam superposed with that of ultrashort pulses generating laser filaments, sounds in real-time the particles generated by the filaments [11]: Their size and number density strongly depend on local, or even micro-local conditions. Such information could for example help improving highresolution weather forecast, or better understanding the process of cloud formation and precipitation.

\section{Conclusion and outlook}

The last two years have seen the emergence of laser-induced water condensation in the atmosphere as a new potential field of applications for ultrashort laser pulses, that might have a strong impact on cloud seeding. The observation of the phenomenon in various conditions by several groups is now well established, and some basic process at play are identified. However, understanding the full complexity of the different pathways contributing to this mechanism constitutes the most challenging question ahead in this field. Both the aerosol microphysics and the plasma photochemistry have to provide a deeper view and understanding of laser-generated particles from their nucleation to their ultimate evolution.

The second challenge ahead regards the potential application of these results to the atmospheric seeding of clouds. Assessing its feasibility on a sufficiently large scale requires further knowledge on the efficiency of laser-induced condensation in various atmospheric conditions, which would enable realistic modelling of the observed particle nucleation and growth and allow determining the cloud types, regions, and conditions in which precipitation enhancement may be expected. Finally, the ability of the lasers to seed macroscopic cloud volumes has to be confirmed, so as to define realistic strategies for beam emission and sweeping. These strategies will then have to be tested in real scale during atmospheric campaigns.

\section{Acknowledgements}

Most or our results discussed in this review have involved members of the Teramobile team, especially at the Free University of Berlin, University of Lyon and University of 
Geneva. We would like to thank them for our excellent collaboration and common work. This work was supported by the Swiss NSF (Grant No. 20021-125315).

\section{References}

1 Zikeev, N.T., Doumani, G.A. 1967. Weather Modification in the Soviet Union, 19461966; A Selected Annotated Bibliography. Washington, DC: Libr. Congr., Sci. Technol. Div.

2 Langmuir, I. Growth of particles in smokes and clouds and the production of snow from supercooled clouds. 1947 Science 106505

3 Schaefer, V. J. Localized effects induced by seeding supercooled clouds with dry ice and silver iodide, 1950 Science 112 455-456

4 Schaefer, V.J. The production of ice crystals in a cloud of supercooled water droplets. 1946 Science $104457-59$

5 Simpson, J., Brier, G.W., Simpson, R.H. Stormfury cumulus seeding experiment 1965: Statistical analysis and main results. 1967 J. Atmos. Sci., 24 508-521.

6 Saleeby, SM, Cotton, W.R., Fuller, J.D. The Cumulative Impact of Cloud Droplet Nucleating Aerosols on Orographic Snowfall in Colorado. $2011 \mathrm{~J}$. Appl. Meteor. Climatol. 50, 604-625.

7 Bruintjes, R. T. A Review of Cloud Seeding Experiments to Enhance Precipitation and Some New Prospects. 1999 Bull. Amer. Meteor. Soc. 80 805-820

8 Qiu, J. and Cressey, D. Taming the sky. 2008 Nature 453 970-974

9 US National Research Council. 2003 Critical Issues in Weather Modification Research (National Academies).

10 Petit, Y., Henin, S., Kasparian, J., Wolf, J.-P. Production of ozone and nitrogen oxides by laser filamentation. 2010 Appl. Phys. Lett. 97021108

11 Rohwetter, P., Kasparian, J., Stelmaszczyk, K., Hao, Z.Q., Henin, S., Lascoux, N., Nakaema, W.M., Petit, Y., Queißer, M., Salamé, R., Salmon, E., Wöste, L., Wolf, J.-P. Laser-induced water condensation in air. 2010 Nature Photonics 4 451-456 
12 Henin, S., Petit, Y., Rohwetter, P., Stelmaszczyk, K., Hao, Z.Q., Nakaema, W. M., Vogel, A., Pohl, T., Schneider, F., Kasparian, J., Weber, K., Wöste, L., Wolf, J.P. Field measurements suggest mechanism of laser-assisted water condensation 2011 Nature Communications 2456

13 Pruppacher, H. R. and Klett, J. D. 1997 Microphysics of clouds and precipitation, Kluwer Academic Publishers

14 Seinfeld, J. H. and Pandis, S. N. 2006 Atmospheric chemistry and physics - From air pollution to climate change. 2nd Edition, Wiley, Hoboken, New Jersey.

15 Denbigh, K. The Principles of Chemical Equilibrium, 4th ed., Cambridge Univ. Press, Cambridge, UK (1981)

$16 \mathrm{Yu}, \mathrm{F}$. Modified Kelvin-Thomson equation considering ion-dipole interaction: Comparison with observed ion-clustering enthalpies and entropies. 2005 The Journal of Chemical Physics 122 084503-8

17 Reiss, H. The Kinetics of Phase Transitions in Binary Systems. 1950 The Journal of Chemical Physics 18840

$18 \mathrm{Yu}$, F. and Turco, F. P. From molecular clusters to nanoparticles: Role of ambient ionization in tropospheric aerosol formation. $2001 \mathrm{~J}$. Geophys. Res. 106, 4797-4814

$19 \mathrm{Yu}, \mathrm{F}$. From molecular clusters to nanoparticles: second-generation ion-mediated nucleation model, 2006 Atmos. Chem. Phys. 6, 5193-5211

20 Jaenicke, R. 'Tropospheric Aersosols'. In: Aerosol-Cloud-Climate Interactions. Ed. by P. V. Hobbs. Burlington, MA: Academic Press (1993), 1-31

21 Metzger, A., Verheggen, B., Dommen, J., Duplissy, J., Prevot, A.S.H., Weingartner, E., Riipinen, I., Kulmala, M., Spracklen, D.V., Carslaw, K.S. and Baltensperger, U. Evidence for the role of organics in aerosol particle formation under atmospheric conditions. 2010 Proceedings of the National Academy of Sciences 107 6646-6651

22 Spracklen, D.V., Carslaw, K.S., Kulmala, M., Kerminen, V.-M., Sihto, S.-L., Riipinen, I., Merikanto, J., Mann, G.W., Chipperfield, M.P., Wiedensohler, A., Birmili, W. and 
Lihavainen, H. Contribution of particle formation to global cloud condensation nuclei concentrations. 2008 Geophysical Research Letters 35 L06808

23 Hobbs, P. V. 'Aerosol-Cloud Interactions'. In: Aerosol-Cloud-Climate Interactions. Ed. by P. V. Hobbs. Burlington, MA: Academic Press (1993), 33-73

24 Wilson, C.T.R. On a Method of Making Visible the Paths of Ionising Particles through a Gas. 1911 Proc. R. Soc. Lond. A. 85 285-288

25 Thomson, J. J. 1906 Conduction of Electricity through Gases, Cambridge University Press, London

26 Tohmfor, G. and Volmer, M. Die Keimbildung unter dem Einfluß elektrischer Ladungen. 1938 Ann. Phys. 425 109-131

27 Pérez, A. and Rubio, A., A molecular dynamics study of water nucleation using the TIP4P/2005 model. 2011 J. Chem. Phys. 135, 244505

28 Hirsikko, A. et al. Atmospheric ions and nucleation: a review of observations, 2011 Atmos. Chem. Phys. 11 767-798

29 Duplissy J. et al. Results from the CERN pilot CLOUD experiment, 2010 Atmos. Chem. Phys. 10 1635-1647

30 Braun, A., Korn, G., Liu, X., Du, D., Squier, J., Mourou, G. Self-channeling of highpeak-power femtosecond laser pulses in air, 1995 Optics Letters 20 73-75

31 Couairon, A. and Mysyrowicz, A. Femtosecond filamentation in transparent media. 2007 Phys. Rep. 44 47-189

32 Bergé, L., Skupin, S., Nuter, R., Kasparian, J., Wolf, J.-P., Ultrashort filaments of light in weakly-ionized, optically-transparent media. 2007 Rep. Prog. Phys. 70 1633-1713

33 Chin, S. L. et al. The propagation of powerful femtosecond laser pulses in optical media: physics, applications, and new challenges. 2005 Can. J. Phys. 83 863-905

34 La Fontaine, B., Vidal, F., Jiang, Z., Chien, C. Y., Comtois, D., Desparois, A., Johnson, T. W., Kieffer, J.-C., and Pépin, H. Filamentation of ultrashort pulse laser beams 
resulting from their propagation over long distances in air, 1999 Physics of Plasmas, 6 $1615-1621$

35 Becker, A., Aközbek, N., Vijayalakshmi, K., Oral, E., Bowden, C. M., and Chin, S. L., 2001 Appl. Phys. B: Lasers Opt. 73287

36 Daigle, J.-F., Jaron-Becker, A., Hosseini, S., Wang, T.-J., Kamali, Y., Roy, G., Becker, A., and Chin, S. L. Intensity clamping measurement of laser filaments in air at 400 and 800 nm, 2010 Physical Review A, 82, 023405

37 Kasparian, J., Sauerbrey, R., and Chin, S. L., 2000 Appl. Phys. B: Lasers Opt. 71877

38 Béjot, P., Kasparian, J., Henin, S., Loriot, V., Vieillard, T., Hertz, E., Faucher, O., Lavorel, B., and Wolf, J.-P. Higher-order Kerr terms allow ionization-free filamentation in gases, 2010 Physical Review Letters 104103903

39 Béjot, P., Hertz, E., Lavorel, B., Kasparian, J., Wolf, J.-P., and Faucher, O. Transition from plasma- to Kerr-driven laser filamentation, 2011 Physical Reveiw Letters 106 243902

40 Shen, Y. R., 1984 The Principles of Nonlinear Optics (Wiley-Interscience, New York), pp. 303-324.

41 Méjean, G., Kasparian, J., Yu, J., Salmon, E., Frey, S., Wolf, J.-P., Skupin, S., Vinçotte, A., Nuter, R., Champeaux, S., and Bergé, L. Multifilamentation transmission through fog, 2005 Physical Review E 72 026611-026611

42 Henin, S., Petit, Y., Kasparian, J., Wolf, J.-P., Jochmann, A., Kraft, S. D., Bock, S., Schramm, U., Sauerbrey R., Nakaema, W. M., Stelmaszczyk, K., Rohwetter, P., Wöste, L., Soulez, C.-L., Mauger, S., Bergé, L., Skupin, S. Saturation of the filament density of ultrashort intense laser pulses in air, Applied Physics B, 100, 77 (2010)

43 Petit, Y., Henin, S., Nakaema, W. M., Béjot, P., Jochmann, A., Kraft, S. D., Bock, S., Schramm, U., Stelmaszczyk, K., Rohwetter, P., Kasparian, J., Sauerbrey R., Wöste, L., Wolf, J.-P. 1-J white-light continuum from 100-TW laser pulses, 2011 Physical Review $A \mathbf{8 3} 013805$ 
44 Rodriguez, M. et al. Kilometer-range non-linear propagation of femtosecond laser pulses, 2004 Phys. Rev. E 69036607

45 Méchain, G., Couairon, A., André, Y.-B., D’Amico, C., Franco, M., Prade, B., Tzortzakis, S., Mysyrowicz, A., Sauerbrey R. Long-range self-channeling of infrared laser pulses in air: a new propagation regime without ionization, 2004 Applied Physics $B 79379$

46 Wille, H., Rodriguez, M., Kasparian, J., Mondelain, D., Yu, J., Mysyrowicz, A., Sauerbrey R., Wolf, J.-P., and Wöste, L. Teramobile: a mobile femtosecond-terawatt laser and detection system, 2002 European Physical Journal - Applied Physics 20 183190

47 Strickland, D., and Mourou, G. Compression of amplified chirped optical pulses, 1985 Optics Communications 56 219-219

48 Liu, W., Théberge, F., Arévalo, E., Gravel, J.-F., Becker, A., and Chin, S. L. Experiment and simulations on the energy reservoir effect in femtosecond light filaments, 2005 Optics Letters 30 2602-2604

49 Courvoisier, F., Boutou, V., Kasparian, J., Salmon, E., Méjean, G., Yu, J., and Wolf, J.P. Light filaments transmitted through clouds, 2003 Applied Physics Letters 83 213-215

50 Kolesik, M., and Moloney, J. V., Self-healing femtosecond light filaments, 2004 Optics Letters, 29, 590-592

51 Skupin, S., Bergé, L., Peschel, U., and Luderer, F. Interaction of femtosecond light filaments with obscurants in aerosols, 2004 Physical Review Letters 93 023901-023901

52 Méchain, G., Méjean, G., Ackermann, R., Rohwetter, P., André, Y.-B., Kasparian, J., Prade, B., Stelmaszczyk, K., Yu, J., Salmon, E., Winn, W., Schlie, L. A., Mysyrowicz, A., Sauerbrey R., Wöste, L., and Wolf, J.-P. Propagation of fs-TW laser filaments in adverse atmospheric conditions, 2005 Applied Physics B 80 785-789

53 Ackermann, R., Méjean, G., Kasparian, J., Yu, J., Salmon, E., Wolf, J.-P. Laser filaments generated and transmitted in highly turbulent air, 2006 Optics Letters 31 8688 
54 Salamé, R., Lascoux, N., Salmon, E., Kasparian, J., and J. P. Wolf Propagation of laser filaments through an extended turbulent region, 2007 Applied Physics Letters 91 171106

55 Kasparian, J. et al. White-light filaments for atmospheric analysis. 2003 Science 301, $61-64$

56 Kasparian, J., and Wolf, J.-P. Physics and applications of atmospheric nonlinear optics and filamentation. 2008 Opt. Express 16, 466-493

57 Kamali, Y., Daigle, J.-F., Théberge, F., Châteauneuf, M., Azarm, A., Chen, Y., Marceau, C., Lessard, S.C., Lessard, F., Roy, G., Dubois, J., Chin, S.L. Remote sensing of trace methane using mobile femtosecond laser system of $T \& T$ Lab. 2009, Optics Communications 282, 2062-2065

58 Alfano, R. R., 2006 The supercontinuum laser source: fundamentals with updated references, Springer, New York,

59 Maioli, P., Salamé, R., Lascoux, N., Salmon, E., Béjot P., Kasparian, J., and Wolf, J.-P. Ultraviolet-visible conical emission by multiple laser filaments, 2009 Optics Express 17 $4726-4731$

60 Théberge, F., Châteauneuf, M., Ross, V., Mathieu, P., and Dubois, J. Ultrabroadband conical emission generated from the ultraviolet up to the far-infrared during the optical filamentation in air, 2008 Optics Letters 33 2515-2517

61 Measures, R.M. Laser remote sensing - Fundamentals and applications. 1984: Wiley Interscience.

62 Méjean, G., Kasparian, J., Salmon, E., Yu, J., Wolf, J.-P., Bourayou, R., Sauerbrey R., Rodriguez, M., Wöste, L., Lehmann, H., Stecklum, B., Laux, U., Eislöffel, J., Scholz, A., Hatzes, A. P. Towards a supercontinuum-based infrared Lidar, 2003, Applied Physics B 77 357-359

63 Galvez, M. C., Fujita, M., Inoue, N., Moriki, R., Izawa, Y., Yamanaka, C. Threewavelength backscatter measurement of clouds and aerosols using a white light lidar system, 2002 Japanese journal of applied physics 41 L284-L286 
64 Bourayou, R., Méjean, G., Kasparian, J., Rodriguez, M., Salmon, E., Yu, J., Lehmann, H., Stecklum, B., Laux, U., Eislöffel, J., Scholz, A., Hatzes, A. P., Sauerbrey R., Wöste, L., and Wolf, J.-P. White-light filaments for multiparameter analysis of cloud microphysics, 2005 Journal of The Optical Society of America B 22369

65 Méjean, G., Kasparian, J., Yu, J., Frey, S., Salmon, E., Wolf, J.-P. Remote Detection and Identification of Biological Aerosols using a Femtosecond Terawatt Lidar System, 2004, Applied Physics B 78 535-537

66 Hill, S. C., Boutou, V., Yu, J., Ramstein, S., Wolf, J.-P., Pan, Y.-L., Holler, S., and Chang, R. K. Enhanced backward-directed multiphoton-excited fluorescence from dielectric microspheres, 2000 Physical Review Letters 85 54-57

67 Luo, Q., Xu, H. L., Hosseini, S. A., Daigle, J. F., Theberge, F., Sharifi, M., and Chin, S. L. Remote sensing of pollutants using femtosecond laser pulse fluorescence spectroscopy, 2006 Applied Physics B-Lasers and Optics 82 105-109

68 Gravel, J.-F., Luo, Q., Boudreau, D., Tang, X.P., Chin, S. L. 2004 Anal. Chem. 764799

69 Stelmaszczyk, K., Rohwetter, P., Méjean, G., Yu, J., Salmon, E., Kasparian, J., Ackermann, R., Wolf, J.-P., and Wöste, L. Long-distance remote laser-induced breakdown spectroscopy using filamentation in air, 2004 Applied Physics Letters 85 3977

70 Tzortzakis, S., Anglos, D., Gray, D. Ultraviolet laser filaments for remote laser-induced breakdown spectroscopy (LIBS) analysis: applications in cultural heritage monitoring, 2006 Optics Letters 31 1139-1141

71 Chin, S. L., Xu, H., Luo, Q., Théberge, F., Liu, W., Daigle, J.F., Kamali, Y., Simard, P., Bernhardt, J., Hosseini, S., Sharifi, M., Méjean, G., Azarm, A., Marceau, C., Kosareva, O., Kandidov, V., Aközbek, N., Becker, A., Roy, G., Mathieu, P., Simard, J., Châteauneuf, M., Dubois, J. Filamentation "remote" sensing of chemical and biological agents/pollutants using only one femtosecond laser source, 2009 Applied Physics B: Lasers and Optics 95 1-12 
72 Uchida, S., Shimada Y., Yasuda, H., Motokoshi, S., Yamanaka, C., Yamanaka, T., Kawasaki, Z., Tsubakimoto, K. Laser-triggered lightning in field experiments, 1999. Journal of Optical Technology, 66, 199

73 Apollonov, V., Kazakov, K., Pletnyev, N., Sorochenko, V. AHPLA’99 Paper 3886-34

74 Pépin, H., Comtois, D., Vidal, F., Chien, C. Y., Desparois, A., Johnston, T. W., Kieffer, J. C., Fontaine, B. L., Martin, F., Rizk, F. A. M., Potvin, C., Couture, P., Mercure, H. P., Bondiou-Clergerie, A., Lalande, P., and Gallimberti, I. Triggering and guiding highvoltage large-scale leader discharges with sub-joule ultrashort laser pulses, 2001 Physics of Plasmas 8 2532-2539

75 Rodriguez, M., Sauerbrey R., Wille, H., Wöste, L., Fujii, T., André, Y.-B., Mysyrowicz, A., Klingbeil, L., Rethmeier, K., Kalkner, W., Kasparian, J., Salmon, E., Yu, J., and Wolf, J.-P. Megavolt discharges triggered and guided with laser filaments, 2002 Optics Letters 27 772-774

76 Rambo, P., Schwarz; J., and Diels, J.-C. High-voltage electrical discharges induced by an ultrashort-pulse UV laser system, 2001 Journal of Optics A: Pure and applied optics 3 146-158

77 Méjean, G., Ackermann, R., Kasparian, J., Salmon, E., Yu, J., Wolf, J.-P., K. Rethmeier, Kalkner, W., Rohwetter, P., Stelmaszczyk, K., and Wöste, L. Improved laser triggering and guiding of megavolt discharges with dual fs-ns pulses, 2006 Applied Physics Letters $\mathbf{8 8}$ 021101-021101

78 Liu, X.-L., Lu, X., Ma, J.-L., Feng, L.-B., Ge, X.-L., Zheng, Y., Li, Y.-T., Chen, L.-M., Dong, Q.-L., Wang, W.-M., Wang, Z.-H., Teng, H., Wei, Z.-Y., and Zhang, J., Long lifetime air plasma channel generated by femtosecond laser pulse sequence. 2012 Optics Express 20, 5968-5973

79 Kasparian, J., Ackermann, R., André, Y.-B., Méchain, G., Méjean, G., Prade, B., Rohwetter, P., Salmon, E., Stelmaszczyk, K., Yu, J., Mysyrowicz, A., Sauerbrey R., Wöste, L., Wolf, J.-P. Electric Events Synchronized with Laser Filaments in Thunderclouds, 2008 Optics Express 16 5757-5763 
80 Kasparian, J., Ackermann, R., André, Y.-B., Méchain, G., Méjean, G., Prade, B., Rohwetter, P., Salmon, E., Stelmaszczyk, K., Yu, J., Mysyrowicz, A., Sauerbrey R., Wöste, L., and Wolf, J.-P. Progress towards lightning control using lasers, 2008 Journal of the European Optical Society: Rapid Publications 308035

81 Sugiyama, K., Fujii, T., Miki, M., Yamaguchi, M., Zhidkov, A., Hotta, E., Nemoto, K. Laser-filament-induced corona discharges and remote measurements of electric fields 2009 Optics Letters 34 2964-2966

82 Ju, J., Liu, J., Wang, C., Sun, H., Wang, W., Ge, X., Li, C., Chin, S.L., Li, R., Xu, Z. Laser-filamentation-induced snowfall in a cloud chamber. 2012 Optics Letters, Early posting, Doc. ID 157795

83 Yoshihara, K. Laser-induced Mist and Particle Formation from Ambient Air: A Possible New Cloud Seeding Method, 2005 Chemistry Letters 341370

84 Petrarca, M., Henin, S., Stelmaszczyk, K., Bock, S., Kraft, S., Schramm, U., Vaneph, C., Vogel, A., Kasparian, J., Sauerbrey R., Weber, K., Wöste, L., and Wolf, J.-P. Multijoule scaling of laser-induced condensation in air, 2011 Applied Physics Letters 99 141103

85 Méjean, G., Kasparian, J., Yu, J., Salmon, E., Frey, S., Wolf, J.-P., Skupin, S., Vinçotte, A., Nuter, R., Champeaux, S., Bergé, L., 2005 Physical Review E 72026611

86 Henin, S., Petit, Y., Kasparian, J., Wolf, J.-P., Jochmann, A., Kraft, S. D., Bock, S., Schramm, U., Sauerbrey R., Nakaema, W. M., Stelmaszczyk, K., Rohwetter, P., Wöste, L., Soulez, C.-L., Mauger, S., Bergé, L., and Skupin, S. Saturation of the filament density of ultrashort intense laser pulses in air, 2010 Applied Physics B 10077

87 Yoshino, K., Parkinson, W. H., Ito, K., Matsui, T. 2005 J. Mol. Spec. 229238

88 Petit, Y., Henin, S., Kasparian, J., Wolf, J. P., Rohwetter, P., Stelmaszczyk, K., Hao, Z. Q., Nakaema, W. M., Wöste, L., Vogel, A., Pohl, T., and Weber, K. Influence of pulse duration, energy, and focusing on laser-assisted water condensation 2011 Applied Physics Letters 98041105

89 Richards, P. G., Torr, D. G., Torr, M. R. 1981 J. Geophys. Res. 861495 
90 Zipf, E. C., Espy, P. J., Boyle, C. F., 1980 J. Geophys. Res. 85687

91 Yoshihara, K., Takatori, Y., Miyazaki, K., and Kajkii, Y. Ultraviolet light-induced water-droplet formation from wet ambient air, 2007 Proceedings of the Japan Academy, Series B $\mathbf{8 3} 320-325$

92 Kerminen, V.-M., Wexler, A. S., Potukuchi, S. 1997 J. Geophys. Res. 102 D3, 37153724

93 Koop, T., Luo, B., Biermann, U. M., Crutzen, P. J., and Peter, T., 1997 J. Phys. Chem. A 101 1117-1133

94 Kossyi, I. A., Kostinsky, A. Y., Matveyev, A. A., Silakov, V. P., Kinetic scheme of the non-equilibrium discharge in nitrogen-oxygen mixtures, 1992 Plasma Sources Sci. Technol. $1207-221$

95 Xu, H.L., Azarm, A., Bernhardt, J., Kamali, Y., and Chin, S. L., 2009 Chem. Phys. 360 171

96 Dotan, I., Hierl, P. M., Morris, R. A., Viggiano, A. A., Int. 1997 J. Mass Spectrom. Ion Process. 167/168 223-230

97 Kulmala, M., Laaksonen, A., Korhonen, P., Vesala, T., Ahonen, T., Barrett, J. C. The Effect of Atmospheric Nitric Acid Vapor on Cloud Condensation Nucleus Activation. 1993 J. Geophys. Res. 98 22949-22958

98 Donaldson, D. J., George, C., Vaida, V., Environ. 2010 Sci. Technol. 445321

99 Frost, G. J., Ellison, G. B., Vaida, V., 1999 J. Phys. Chem. A 10310169

100 Vaida, V., 2011 J. Chem. Phys. 135020901

101 Byers Brown, W., 1995 Chem. Phys. Lett. 23594

102 Wyslouzil, B.E., Carleton, K.L., Sonnenfroh, D.M., Rawlins, W.T. and Arnold, S. Observation of hydration of single, modified carbon aerosols. 1994 Geophys. Res. Lett. $212107-2110$ 
103 Vlasenko, A., Sjogren, S., Weingartner, E., Stemmler, K., Gäggeler, H.W. and Ammann, M. Effect of humidity on nitric acid uptake to mineral dust aerosol particles. 2006 Atmos. Chem. Phys. 6 2147-2160

104 Schwier, A., Sareen, N., Lathem, T., Nenes, A., McNeill, V. F. Ozone oxidation of oleic acid surface films decreases aerosol cloud condensation nuclei activity. 2011 Journal of Geoophysical Research 116 D16202

105 Mather, G. K., Terblanche, D. E., Steffens, F. E., Fletcher, L. Results of the South African Cloud-Seeding Experiments Using Hygroscopic Flares. 1997 Journal of Applied Meteorology 36 1433-1447

106 Reisin, T., Tzivion, S., Levin, Z. Seeding Convective Clouds with Ice Nuclei or Hygroscopic Particles: A Numerical Study Using a Model with Detailed Microphysics 1996 Journal of Applied Meteorology 36 1416-1434

107 Cooper, W. A., Bruintjes, R. T., and Mather, G. K. Some calculations pertaining to hygroscopic seeding with flares. $1997 \mathrm{~J}$. Appl. Meteor. 36, 1449-1469.

108 Levin, Z., Cotton, W.R., Aerosol Pollution Impact on Precipitation: A Scientific Review, Springer, Heidelberg (2009)

109 Hecht, J., Photonics frontiers: The Extreme Light Infrastructure: The ELI aims to break down the vacuum. 2011 Laser Focus World 01/2011

110 Chambaret, J-P., Chekhlov, O., Cheriaux, G., Collier, J., Dabu, R., Dombi, P., Dunne, A.M., Ertel, K., Georges, P., Hebling, J., Hein, J., Hernandez-Gomez, C., Hooker, C., Karsch, S., Korn, G., Krausz, F., Le Blanc, C., Major, Z., Mathieu, F., Metzger, T., Mourou, G., Nickles, P., Osvay, K., Rus, B., Sandner, W., Szabo, G., Ursescu, D., Varju, K. Extreme Light Infrastructure: architecture and major challenges. 2010 Proceedings of SPIE $772177211 \mathrm{D}$ 